\title{
Intensive Care Nurses' Knowledge regarding Ventilator Associated Pneumonia
}

\author{
Dr.Thenmozhi. $\mathrm{P}^{1} \&$ Priyanka.J $\mathrm{J}^{2}$ \\ ${ }^{1}$ Associate Professor, Saveetha College of Nursing, SIMATS, Chennai Tamilnadu, India. \\ ${ }^{2}$ B.Sc.(N) IV Year, Saveetha College of Nursing, SIMATS, Chennai, Tamilnadu, India. \\ Corresponding Author Email: thenmozhi.sethu@gmail.com
}

Background: VAP is one of the most significant causes of morbidity and mortality in mechanically ventilated critically ill patients. Lack of knowledge on VAP is highly influenced on incidence of VAP. Objective: The objective of the study was to assess the level of knowledge regarding VAP among the staff nurses working in the intensive care unit. Methods: Non-experimental cross sectional research design was used with 50 samples at selected hospital. The tool used for the study to collect the data was demographic variables and structured multiple choice questionnaires regarding VAP. Data was collected by self-administered method. Results: Out of 50 samples, 38 (76\%) had adequate knowledge, seven (14\%) had moderately adequate knowledge and five (10\%) had inadequate knowledge and there was no significant association with selected demographic variables Conclusion: The findings of the present study concluded that there was no cent percent adequate knowledge on VAP. Organize regular and periodical continuing nursing education or on the job training on ventilator associated pneumonia for Staff nurses working in the intensive care unit to impart knowledge.

Keywords: Ventilator Associated Pneumonia, Mechanical Ventilation, Staff Nurses, Intensive Care Unit, Knowledge.

\section{INTRODUCTION}

One of the lifesaving interventions in the critical care unit for the patients with respiratory failure is Mechanical ventilation. Ventilator-associated pneumonia (VAP) is the second most common nosocomial infection in the intensive care unit and the most common in mechanically ventilated patients $(1,2)$. VAP is a type of hospital-acquired pneumonia that occurs more than 48 hours after endotracheal intubation or tracheostomy. This can be further classified into early onset which is within the first 96 hours of mechanically ventilation and late onset if it occurs more than 96 hours after the initiation of mechanically ventilation (3). VAP is one of the most significant causes of morbidity and mortality in mechanically ventilated critically ill patients (4). VAP contributes to approximately half of all cases of hospital-acquired pneumonia $(5,6)$. It is estimated to occur in 9-27 \% of all mechanically ventilated patients, with the highest risk being early in the course of hospitalization (7).

A number of evidence based strategies have been developed for the prevention of ventilator associated pneumonia. An incidence of VAP can be reduced by adopting care bundle approach, well equipped ICU, good number of ICU experts, advanced medications and active infection control team. Nurses are the health care personnel in the ICU, who caring the patients round the clock. If nurses are familiar with knowledge of prevention of VAP, they can apply evidences based practices and thus reduce the morbidity and mortality rate associated with VAP. Lack of knowledge may be a potential barrier to adherence to evidence-based guidelines for the prevention of VAP. Nurses' knowledge regarding ventilator associated pneumonia is having high impact on reduction of VAP among intubated patients (8).

Several recent surveys reported that there is a substantial lack of knowledge among intensive care nurses concerning evidence-based strategies for preventing VAP (9). Hence the study was conducted with the aim to assess the level of knowledge regarding VAP among the staff nurses working in the intensive care unit. 


\section{METHODS AND MATERIALS}

Quantitative approach by using non-experimental cross sectional research design was used to assess the level of knowledge on VAP with 50 samples at selected hospital. The samples who met the inclusion criteria were selected by convenient sampling technique from medical, surgical, cardiac, respiratory and pediatric intensive care unit and who were not interested to participate in the study were excluded. The tool used for the study to collect the data was demographic variables and structured multiple choice questionnaires regarding VAP. Formal permission was obtained from the hospital authority. The nurses who consented orally and willing to participate were informed about the purpose of the study and were assured about confidentiality and anonymity. Data was collected by self-administered method. The collected data prepared for analysis using Microsoft excel and were analyzed by using descriptive and inferential statistics. $P$ values less than 0.05 were considered statistically significant.

\section{RESULTS}

Table 1: Frequency and percentage distribution of demographic variables among staff nurses $(n=50)$

\begin{tabular}{|c|c|c|}
\hline DEMOGRAPHIC VARIABLES & Frequency & Percentage \\
\hline \multicolumn{3}{|l|}{ 1.Age } \\
\hline a) 21-25 years & 16 & $32 \%$ \\
\hline b) $26-30$ years & 24 & $48 \%$ \\
\hline c) $31-35$ years & 10 & $20 \%$ \\
\hline \multicolumn{3}{|l|}{ 2. Gender } \\
\hline a) Male & 15 & $30 \%$ \\
\hline b) Female & 35 & $70 \%$ \\
\hline \multicolumn{3}{|l|}{ 3. Income } \\
\hline a) $12000-15000$ & 31 & $62 \%$ \\
\hline b) $15000-18000$ & 13 & $26 \%$ \\
\hline c) $>18000$ & 6 & $12 \%$ \\
\hline \multicolumn{3}{|l|}{ 4. Work Experience } \\
\hline a) $<1$ year & 15 & $30 \%$ \\
\hline b) 1-3 years & 21 & $42 \%$ \\
\hline c) 3-5 years & 14 & $28 \%$ \\
\hline \multicolumn{3}{|l|}{ 5. Educational Qualification } \\
\hline a) GNM & 24 & $48 \%$ \\
\hline
\end{tabular}




\begin{tabular}{|c|l|l|}
\hline b) B.Sc(N) & 26 & $52 \%$ \\
\hline 6. Working Ward & 12 & $24 \%$ \\
a) Medical ICU & 13 & $26 \%$ \\
b) Surgical ICU & 7 & $14 \%$ \\
c) Respiratory ICU & 12 & $24 \%$ \\
d) Cardiac ICU & 6 & $12 \%$ \\
e) Pediatric ICU & & \\
\hline
\end{tabular}

Table-I: Shows the distribution of various demographic variables among 50 intensive care unit nurses. that $32 \%$ of staff nurses are between the age group of 21-25 years, Majority 70\% of the nurses were male, $28 \%$ had 3-5 years of experience, more than $50 \%$ were graduate nurses and majority of nurses are working in medical, surgical, and cardiac ICU.

Figure-I: Percentage distribution of level of knowledge on VAP

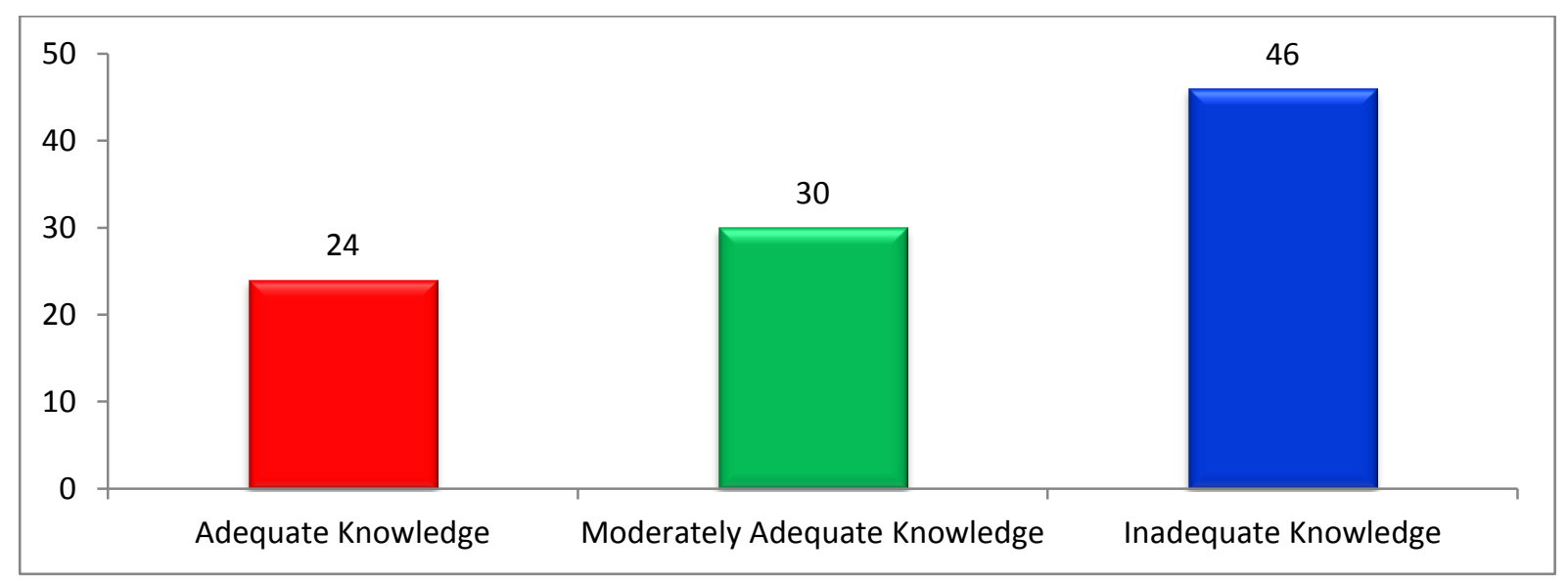

Out of 50 samples, 12(24\%) had adequate knowledge, 15 (30\%) had moderately adequate knowledge and 23 (46\%) had inadequate Knowledge.

Table II. Mean and Standard Deviation of Level of Knowledge regarding VAP ( $\mathrm{n}=50)$

\begin{tabular}{|l|l|l|}
\hline \multicolumn{1}{|c|}{ Level of Knowledge } & \multicolumn{1}{|c|}{ Mean } & \multicolumn{1}{c|}{$\begin{array}{c}\text { Standard } \\
\text { Deviation }\end{array}$} \\
\hline Adequate Knowledge & 17.6 & 1.36 \\
\hline Moderately Adequate Knowledge & 13.2 & 2.75 \\
\hline Inadequate Knowledge & 7.5 & 2.14 \\
\hline
\end{tabular}


The mean value of adequate knowledge was 17.6 with 1.36 standard deviation, moderately adequate knowledge mean was 13.2 with 2.57 standard deviation and inadequate knowledge mean was 7.5 with 2.14 standard deviation as depicted in Table 2 .

Chi square test reveals that there is no significant association between the level of knowledge and the selected demographic variables at the level of $p<0.05$

\section{DISCUSSION}

Ventilator associated pneumonia is the second most common hospital acquired infection next to catheter associated urinary tract infection. Hence the main focus of this study was to assess the knowledge on VAP among intensive care nurses and it was interpreted as adequate knowledge, moderately adequate knowledge and inadequate knowledge. The current study findings revealed that $46 \%$ had inadequate knowledge. Staff nurses experience and educational qualification could have highly influenced their knowledge because $50 \%$ were diploma qualified and less than three years of experience. The present study findings consistent with the study conducted by Ankita sharma reported that no one have excellent knowledge regarding ventilator associated pneumonia, $6 \%$ has good knowledge, $28 \%$ has average knowledge and $66 \%$ has below average knowledge (10). Similarly another study by Faisal Younus et al, who stated that the knowledge of intensive care nurses' on VAP was unsatisfactory (11). In another study conducted by Masoumeh who found that nurses' knowledge of evidence- based guidelines for preventing ventilator-associated pneumonia in intensive care units preventive measures was $51.92 \%$ which was lower (12). The present also found that there was no significant association between the level of knowledge and their demographic variables. Hence the study can be recommended to conduct with large sample, and intervening with educational programme.

\section{CONCLUSION}

The findings of the present study concluded that there was no cent percent adequate knowledge on VAP. Since the level of knowledge on VAP is highly impact on preventing VAP, organize regular and periodical continuing nursing education or on the job training on ventilator associated pneumonia for the staff nurses working in the intensive care unit to impart the knowledge. Staff nurses are motivated to adhere the evidence based practice and care bundle approach to prevent the VAP.

\section{ACKNOWLEDGEMENT}

Authors would like to appreciate participants for their cooperation to complete the study successfully.

\section{CONFLICT OF INTEREST}

Author declares no conflict of interest.

\section{REFERENCES}

1. Hunter JD. Ventilator associated pneumonia. Postgrad Med. 2006; 82:172-178.

2. Muscedere JG, Shorr AF, Jiang $X$, et al. The adequacy and timely empiric antibiotic therapy for ventilator-associated pneumonia and blood stream infection: a meta-analysis. J Crit Care. 2012; 27:322e7. 
3. American Thoracic Society, Infectious Diseases Society of America: Guidelines for the management of adults with hospital-acquired, ventilator-associated, and healthcare-associated pneumonia. Am J Respir Crit Care Med 2005, 171: 388-416.

4. Vincent JL, Bihari DJ, Suter PM, Bruining HA, White J, Nicolas-Chanoin MH, Wolff M, Spencer RC, Hemmer M: The prevalence of nosocomial infection in intensive care units in Europe. JAMA 1995, 274: 639-644.

5. Chastre J, Fagon JY: State of the art: ventilator-associated pneumonia. Am J Respir Crit Care Med 2002, 165: 867-903.

6. Hunter JD: Ventilator associated pneumonia. BMJ 2012, 344: e3325.

7. Afshari A, Pagani L, Harbarth S: Year in review 2011: Critical care - infection. Crit Care 2012, 16: 242-247.

8. Pathmawathi Subramanian, Kee Leong Choy, Suresh VenuGobal, Marzida Mansor, Kwan Hoong. Impact of education on ventilator-associated pneumonia in intensive care unit. Singapore Med J. 2013; 54(5): 1-4.

9. Ali NS. Critical Care Nurses' Knowledge and Compliance with Ventilator Associated Pneumonia Bundle at Cairo University Hospitals. Journal of Education and Practice 2013; 4(15): 66-77.

10. Ankita Sharma. A Descriptive Study to assess the knowledge of staff nurses regarding ventilator associated pneumonia (VAP) among patient admitted in intensive care unit at selected hospital, Jalandhar. IOSR Journal of Nursing and Health Science, 8(2);56-59.

11.https://www.researchgate.net/publication/331198696_Knowledge_of_Intensive_Care_Nurses'_Regarding_Ve ntilator_Association_Pneumonia_at_Kirkuk_City_Hospitals.

12. Masoumeh Bagheri-Nesami , Maryam Amiri. Nurses' knowledge of evidence- based guidelines for preventing ventilator-associated pneumonia in intensive care units. Journal of Nursing and Midwifery sciences, 2014, 1(1): 44-48. 